THURston, J. M. 1954. A survey of wild oats (A. fatua and A. ludoviciana) in England and Wales in 1951. Ann. appl. Biol., 41, 619-636.

THURston, J. M. 1963a. Weed studies. Wild oats. Rep. Rothamsted Exp. Sta. for 1962, 93-94. THURston, J. M. 1963b. Biology and control of wild oats. Rep. Rothamsted Exp. Sta. for 1962, 236-253.

THURSTON, J. M. 1964. Wild oats. Effect of photoperiod on germination. Rep. Rothamsted Exp. Sta. for 1963, 91.

rhURston, J. M. 1966. Wild oats ( $A$. fatua and $A$. ludoviciana). Effect of temperature on dormancy of seeds. Rep. Rothamsted Exp. Sta. for 1965, 102.

TOOLE, E. H., AND COFPMAN, P. A. 1940. Variations in the dormancy of seeds of the wild oat, Avena fatua. 3. Am. Soc. Agron., 32, 631-638.

\title{
CYTOGENETIC STUDIES OF A CHLOROPHYLL MUTANT OF HEXAPLOID WHEAT
}

\author{
RONA PETTIGREW and C. J. DRISCOLL \\ School of Botany, University of New South Wales, Kensington, \\ N.S.W., Australia
}

Received 6.v.70

\section{INTRODUCTION}

ChLOROPHYLl mutants of polyploids are particularly useful for the study of the interaction of duplicated genetic material. In a polyploid species in which aneuploid stocks are available, such as hexaploid wheat, the similarities and differences of loci related to the mutant locus can be examined with the aim of determining what diversification has taken place among homoeologous loci.

This paper reports on such a study of a spontaneous chlorophyll mutant recently described by Pettigrew, Driscoll and Rienits (1969).

\section{Materials and methods}

The yellow mutant of Triticum aestivum L. emend Thell. arose as a spontaneous change at one locus. The mutant form is partially dominant to normal as heterozygotes are yellow-green and homozygous mutant individuals are distinctly yellow. The mutant gene actively supresses chlorophyll formation-it is not merely a deletion since all nullisomics of hexaploid wheat are the normal green colour.

The homozygous mutant is quite vigorous and fully fertile under glasshouse conditions despite its marked deficiency in leaf pigments (Pettigrew, Driscoll and Rienits, loc. cit.). Gametes bearing this mutant allele compete equally well with gametes bearing the normal allele.

The specific chromosome location of the mutant gene was determined by the method of monosomic analysis (Sears, 1953) using the Chinese Spring monosomic lines provided by Dr E. R. Sears, University of Missouri. The conventional monosomic lines were used for 19 of the 21 chromosomes and monoisosomic (long arm) 5D and monoisosomic (short arm) monotelosomic (short arm) 7D for the remaining two chromosomes (conventional monosomics of these last two chromosomes were not on hand at the time of crossing). 
The four ditelocentric lines involving the arms of chromosomes 7A and 7B were used for studying the loci homoeologous with the mutant locus.

The relationship of the yellow mutant with chlorina-1 (Sears and Sears, 1968) was determined by intercrossing the two mutants and observing the $\mathrm{F}_{2}$ population. Chlorina-1 is similar to, but less extreme than, the yellow mutant.

Abbreviations used in the remainder of this paper are mono (monosomic), nulli (nullisomic), monoiso (monoisosomic), monotelo (monotelosomic), and ditelo (ditelosomic).

\section{RESUlts}

The $\mathrm{F}_{2}$ segregation ratio of green : yellow-green : yellow obtained in the monosomic analysis involving chromosomes of homoeologous groups 1 to 6 inclusive conformed with $1: 2: 1$ ratio for each of the 18 populations involved. Thus the mutant gene is not located on any of these chromosomes.

TABLE 1

$F_{2}$ results involving monosomes of homoeologous group 7. (Expected numbers shown in brackets)

\begin{tabular}{llll}
\multicolumn{1}{c}{ Colour class } & Mono 7A & Mono 7B & Mono 7D \\
Green & $3(1.9)$ & $43(56 \cdot 8)$ & $29(36 \cdot 5)$ \\
Yellow-green & - & $27(27 \cdot 2)$ & $19(17.5)$ \\
Pale yellow-green & $40(45 \cdot 2)$ & $93(82.9)$ & $56(53 \cdot 3)$ \\
Yellow & $19(14 \cdot 9)$ & $23(17 \cdot 0)$ & $13(11.0)$ \\
Pale yellow & - & $39(41 \cdot 4)$ & $29(26.6)$ \\
Very pale yellow & - & $2(1 \cdot 7)$ & $0(1 \cdot 1)$
\end{tabular}

The $F_{1}$ progenies of crosses involving all three aneuploids of homoeologous group 7 contained individuals of a new phenotype. The $F_{1}$ progenies involving mono $7 \mathrm{~A}$ and mono $7 \mathrm{~B}$ contained both yellow-green plants and plants which were somewhat paler than the normal yellow-green. Cytological checking showed that the 5 pale yellow-green plants from the mono $7 \mathrm{~B}$ cross and the 2 pale yellow-green plants from the mono $7 \mathrm{~A}$ cross were monosomic. The 6 normal yellow-greens ( 4 for mono $7 \mathrm{~B}, 2$ for mono $7 \mathrm{~A}$ ) were disomic.

The offspring of the cross monoiso monotelo 7D (short arm) $\times$ yellow were all pale yellow-green. These had varying chromosome complements. There were 9 with a monosome and an isochromosome, 6 with a monosome and a telosome, and one monosomic. This last plant was used to obtain the $\mathrm{F}_{2}$ population.

The $\mathrm{F}_{2}$ results of the cross involving mono $7 \mathrm{~A}$ showed the pattern expected in the case involving the critical chromosome (table 1). The three green plants obtained were cytologically checked and found to be nullisomic. Four pale yellow-green plants were also cytologically checked and all were found to be monosomic. The ratio of the three types in this population ( 3 green, 40 pale yellow-green, 19 yellow) agrees with the expected ratio of nullisomics, monosomics and disomics in a population obtained by selfing a monosomic (see table 1 for expected values, $\chi^{2}=2 \cdot 37, P=0 \cdot 20-0 \cdot 30$ ). The different colour classes correspond to the different chromosome complements, therefore the mutant gene is located on chromosome 7A. 
Because of the colour difference between mono 7A individuals possessing a mutant allele and disomic heterozygotes (pale yellow-green and yellowgreen respectively), it can be concluded that the normal allele on $7 \mathrm{~A}$ has a chlorophyll promoting effect which is opposed by the mutant allele.

$\mathrm{F}_{2}$ populations from crosses involving chromosomes $7 \mathrm{~B}$ and $7 \mathrm{D}$ contained more than the three normal colour classes. As well as the usual green, yellowgreen and yellow, a pale yellow-green (as observed in the $F_{1}$ populations), a pale yellow and a very pale yellow class appeared. The pale yellow and very pale yellow seedlings died at the two- or three-leaf stage.

The extra colour classes found in the above two $\mathrm{F}_{2}$ populations can be explained in terms of genes for chlorophyll production on chromosomes 7B and $7 \mathrm{D}$, these genes working in opposition to the mutant gene in a similar manner to the normal allele on 7A.

Cytological examination of 10 pale yellow-green $F_{2}$ individuals from the mono $7 \mathrm{~B}$ population and 6 pale yellow-green $\mathrm{F}_{2}$ individuals from the mono $7 \mathrm{D}$ population showed that all were monosomics. These observations and the $F_{1}$ observations identify the pale yellow-green types as being heterozygous for the mutant gene on 7A and monosomic for either 7B or 7D. They fall into the same colour class as individuals hemizygous for the mutant gene on 7A.

Cytological examination of root tip squashes of 5 pale yellow $\mathrm{F}_{2}$ seedlings of the mono 7B populations and 5 pale yellow seedlings of the mono 7D population showed that all had 41 chromosomes. These are considered to be homozygous for the mutant gene on 7A and monosomic for either $7 \mathrm{~B}$ or 7D.

The very pale yellow individuals seen in the mono 7B $\mathrm{F}_{2}$ population were presumed to be homozygous for the mutant gene and nullisomic for 7B (cytological checking showed that this type had 40 chromosomes).

Further confirmation of these relationsips can be seen by comparing the observed numbers in each colour class with the numbers expected on the basis of $1: 2: 1$ segregation of alleles on chromosome 7A and the ratio of 24 per cent. disomic : 73 per cent. monosomic : 3 per cent. nullisomic for either chromosome 7B or 7D. Table 1 shows that there is a good agreement between observed and expected for both 7B and 7D populations (7B : $\chi^{2}$ $\left.=6 \cdot 89, \mathrm{P}=0 \cdot 20-0 \cdot 30 ; 7 \mathrm{D}: \chi^{2}=3 \cdot 39, \mathrm{P}=0 \cdot 50-0 \cdot 70\right)$.

One class not detected in the $\mathrm{F}_{2}$ was the type heterozygous for the mutant gene and nullisomic for 7B or 7D. This type may have been present but indistinguishable from one of the other colour classes, yellow for example (expected results in table 1 have been calculated on this assumption). This type has subsequently been obtained for both $7 \mathrm{~B}$ and $7 \mathrm{D}$. It is yellow in colour and difficult to distinguish from the homozygous disomic yellow type. It is slightly greener, but cannot be reliably distinguished without cytological examination.

Thus there is a series of colours from green to very pale yellow, the colour depending on the ratio of normal : mutant genes. This is summarised in table 2.

The fact that all $F_{1}$ plants of the cross monoiso monotelo $7 \mathrm{D}$ (short arm) $\times$ yellow were pale yellow-green can be explained by the gene for chlorophyll formation being located on the long arm of 7D. All $F_{1}$ plants were thus hemizygous for this gene. To ascertain which of the arms of chromosomes 7A and 7B carried the chlorophyll production genes, plants 
ditelocentric for each arm of each of these two chromosomes were crossed with the yellow mutant. The results were as follows:

$$
\begin{aligned}
& \text { Ditelo 7A (short arm) } \times \text { yellow } \rightarrow \text { pale yellow-green } \\
& \text { Ditelo 7A (long arm) } \times \text { yellow } \rightarrow \text { yellow-green } \\
& \text { Ditelo 7B (short arm) } \times \text { yellow } \rightarrow \text { pale yellow-green } \\
& \text { Ditelo 7B (long arm) } \times \text { yellow } \rightarrow \text { yellow-green. }
\end{aligned}
$$

Thus the three arms containing homeologous genes for chlorophyll

\begin{tabular}{|c|c|c|}
\hline Genotype & $\begin{array}{l}\text { Ratio of normal: } \\
\text { mutant genes }\end{array}$ & Colour class \\
\hline Heterozygous disomic & $5: 1$ & Yellow-green \\
\hline $\begin{array}{l}\text { Hemizygous mono 7A } \\
\text { Heterozygous mono 7B } \\
\text { Heterozygous mono 7D }\end{array}$ & $\begin{array}{l}4: 1 \\
4: 1 \\
4: 1\end{array}$ & $\begin{array}{l}\text { Pale yellow-green } \\
\text { Pale yellow-green } \\
\text { Pale yellow-green }\end{array}$ \\
\hline $\begin{array}{l}\text { Heterozygous nulli } 7 \mathrm{~B} \\
\text { Heterozygous nulli } 7 \mathrm{D}\end{array}$ & $\begin{array}{l}3: 1 \\
3: 1\end{array}$ & $\begin{array}{l}\text { Yellow (greenish) } \\
\text { Yellow (greenish) }\end{array}$ \\
\hline Homozygous disomic & $4: 2=2: 1$ & Yellow \\
\hline $\begin{array}{l}\text { Homozygous mono } 7 \mathrm{~B} \\
\text { Homozygous mono } 7 \mathrm{D}\end{array}$ & $\begin{array}{l}3: 2=1 \frac{1}{2}: 1 \\
3: 2=1 \frac{1}{2}: 1\end{array}$ & $\begin{array}{l}\text { Pale yellow } \\
\text { Pale yellow }\end{array}$ \\
\hline $\begin{array}{l}\text { Homozygous nulli } 7 D \\
\text { Homozygous nulli } 7 D\end{array}$ & $\begin{array}{l}2: 2=1: 1 \\
2: 2=1: 1\end{array}$ & $\begin{array}{l}\text { Very pale yellow } \\
\text { Very pale yellow }\end{array}$ \\
\hline
\end{tabular}
production are the long arms of chromosomes $7 \mathrm{~A}, 7 \mathrm{~B}$ and $7 \mathrm{D}$.

TABLE 2

Correlation of colour with genetic constitution of plants

The yellow mutant was crossed with Chlorina-1, a similar mutant involving a single gene which is also located on chromosome $7 \mathrm{~A}$. The $\mathrm{F}_{1}$ population was similar to the parents and the $F_{2}$ population, consisting of 121 plants, was also completely of the chlorina type. The range of variation in the $F_{2}$ population was from the less extreme parent colour (chlorina-1) to the more extreme parent colour (yellow), but the variation was slight and contained no plants outside the parental range. Thus chlorina-1 and yellow are allelic mutations of a gene on the long arm of chromosome 7A.

\section{Discussion}

The study of this spontaneous mutation in conjunction with varying doses of the homoeologous chromosomes has allowed detection of three homoeologous loci concerned with the same biological function. Sears (1959) has shown that a similar situation exists with Neatby's virescent and the three chromosomes of homoeologous group 3. Sears and Sears (loc. cit.) have shown that Hermsen's virescent also involves chromosomes of homoeologous group 3. Chromosomes $3 \mathrm{~A}$ and $3 \mathrm{~B}$ both have recessive mutations, the double recessive giving rise to the mutant phenotype. McIntosh and Baker (1968) have shown that lack of the long arm of chromosome 7B allows the expression of an albino mutant. The mutant gene(s) is presumably homoeologous with a gene on the long arm of $7 \mathrm{~B}$. That the long arm 
of 7B is involved is of particular interest since this particular chromosome arm has been shown, in the present study, to have a gene for chlorophyll formation related to the yellow mutant. Thus, for hexaploid wheat, it appears that chlorophyll mutants have a series of two or three homoeologous loci.

The colour series and corresponding dosage series of normal : mutant " alleles", which has been observed over the range of $5: 1$ to $1: 1$, are evidence of the fact that the three different genes are performing an integrated function. Presumably a polyploid could survive equally as well as a diploid with only one representative of this locus, so in time perhaps two of the three loci will be deleted. The current situation may reflect recent formation of this polyploid. However, some divergence has been observed. The pale yellow-green types are very slightly different in colour depending on which chromosome is monosomic. Pigment analyses are being done to put this variation on a quantitative basis.

Since a ratio of 1.5 normal : 1 mutant allele results in lethality, it can be concluded that if such a mutation had occurred in a diploid, where the ratio would have been $1: 1$, it would have been seedling lethal. This situation illustrates the buffering effect of a polyploid series of loci.

The detection of the three specific chromosome arms carrying the three homoeologous loci indicates that these three arms as a whole may be homoeologous. The danger in such a conclusion is that pericentric inversions may have altered the situation as it was immediately after evolutionary divergence. However, the detection of one homoeologous locus such as this means that if homoeologous series of entire arms do exist for homoeologous group 7, there is only one possible combination, viz. the long arms of $7 \mathrm{~A}, 7 \mathrm{~B}, 7 \mathrm{D}$ are homoeologous and the three short arms are homoeologous. The other three possible combinations of entire arm homoeologies have been excluded.

\title{
5. Summary
}

1. The single mutant gene is located on chromosome 7A.

2. There are genes on homoeologous chromosomes $7 \mathrm{~B}$ and $7 \mathrm{D}$ similar to the normal allele of the mutant gene.

3. These three homoeologous genes have a chlorophyll promoting effect whereas the mutant gene has the effect of reducing the amount of chlorophyll in the leaves. The various combinations of the mutant gene and its normal homoeoalleles give rise to a colour series from green to very pale yellow plants depending on the ratio of normal : mutant genes.

4. Ratios of 1.5 normal : 1 mutant gene or lower lead to seedling lethality.

5. The three homoeologous genes for chlorophyll production lie on the long arms of chromosomes 7A, 7B and 7D.

6. This mutant is allelic with chlorina-1.

\begin{abstract}
Acknowledgments.-One of us (R. P.) held a Reserve Bank of Australia Scholarship, while carrying out this research.
\end{abstract}

\section{REFERENGES}

MCINTOSH, R. A., AND BAKER, R. P. 1968. Cytogenetic studies in wheat. II. An analysis of chlorophyll abnormalities in hexaploid wheat. Genet. Res., Camb., 12, 11-19. 
PETTIGREW, R., DRISCOLL, C. J., AND RIENITs, k. G. 1969. A spontaneous chlorophyll mutant in hexaploid wheat. Heredity, 24, 481-487.

SEARs, E. R. 1953. Nullisomic analysis in common wheat. The American Naturalist, Vol. LXXXVII, No. 835, 245-252.

SEARs, E. R. 1959. Neatby's virescent. Genetics, 44, 534.

SEARs, L. M. 8., AND sEARs, E. R. 1968. The mutants Chlorina-1 and Hermsen's virescent. Proc. 3rd Int. Wheat Genetics Symp., 299-304.

\title{
TWIN BIOLOGY
}

\author{
C. D. DARLINGTON \\ School of Botany, University of Oxford
}

Received 18.v.70

TwinNING concerns anyone who may want to study plant or animal reproduction. Whether his concern is anatomical, physiological or genetical, its causes and its consequences need to be weighed and judged. The more we have learnt, however, of these relations, the more complicated they have seemed to become. So much so that experts have learnt to shrink reluctantly from probing them to their genetic depths.

TABLE 1

Frequencies of embryologically classified types of twins in European populations (after Bulmer, 1970, and J. H. Edwards, 1968)

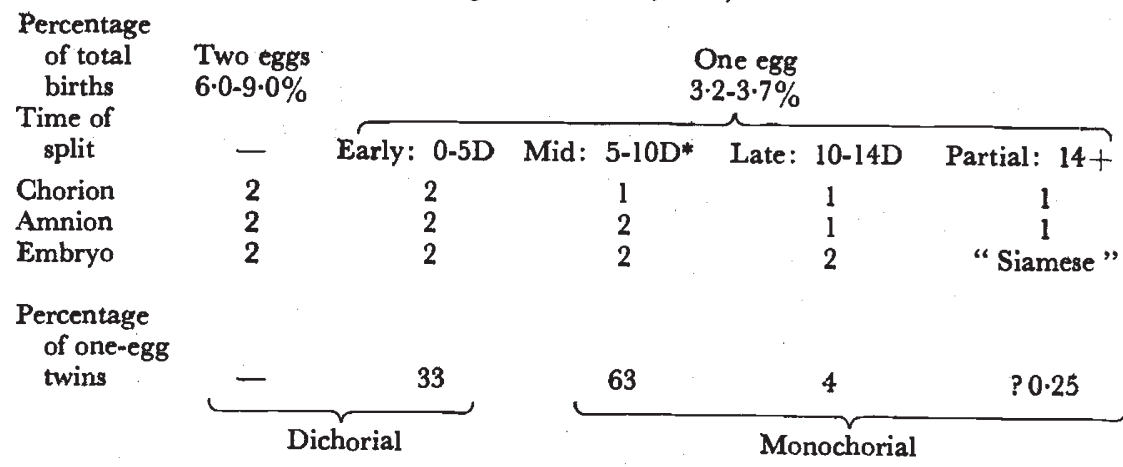

* Between implantation at 5 days and differentiation of the amnion at 10 days.

Dr Bulmer, the most recent investigator, despite his title, shares this reluctance. Still others may share it when faced with his diagram of crossing over (fig. 1.2). Nevertheless, for anyone who wants to go further, by his careful statistical treatment he clears the ground and uncovers some if not all of the pitfalls. It is worth our while therefore to take this opportunity of seeing what the ground looks like today.

Certain principles are clear from the surveys made by Bulmer and earlier by Edwards (table 1). The frequency of one-egg twins can be established only by genetic tests of identity since early splitting gives chorions and amnions as separate as in two eggs twins. The mode of origin therefore has to be deduced from the identity and not the identity from the mode of origin. These tests however are now certain and varied enough to leave little room for error. They allow us to say, on the one hand, that one-egg 